\title{
Improving efficiency of on-site monitoring in multicentre clinical trials by targeting visits
}

\author{
Carol Knott*, Elsa Valdes-Marquez, Martin Landray, Jane Armitage, Jemma Hopewell \\ From 3rd International Clinical Trials Methodology Conference \\ Glasgow, UK. 16-17 November 2015
}

\section{Background}

Monitoring guidance for clinical trials recommends the use of central and on-site monitoring practices. Comparing the efficiency of on-site monitoring visits targeted as a result of central statistical monitoring (CSM) procedures, versus those that were not, could help to improve trial conduct.

\section{Methods}

The monitoring plan in a large long-term multicentre international trial required that sites received routine monitoring visits every nine months. Oversight of this trial was augmented by central statistical monitoring that identified high scoring sites as priority for further investigation. To validate this approach high scoring sites, and some low scoring sites (in the same countries) identified by the country teams as potentially problematic were visited.

\section{Results}

Over a twelve month period 21 sites (12 identified by CSM, 9 others as comparators) received a comprehensive monitoring visit from the senior monitor. Only 1 site identified by CSM had no findings, versus 7 of the comparator sites. Minor findings indicative of 'sloppy practice' were identified at 12 sites (10 CSM versus 2 comparator). At 1 site identified by CSM there were serious findings indicative of an under-performing site.

\section{Conclusion}

On-site visits triggered by CSM are more efficient than undirected routine visits. Furthermore, information from CSM can help focus the nature of on-site visits and any interventions required to improve site quality, e.g. additional training on data collection or event reporting.

Clinical Trial Service Unit, Nuffield Department of Population Health, University of Oxford, Oxford, UK

Submit your next manuscript to BioMed Central and take full advantage of:

- Convenient online submission

- Thorough peer review

- No space constraints or color figure charges

- Immediate publication on acceptance

- Inclusion in PubMed, CAS, Scopus and Google Scholar

- Research which is freely available for redistribution 